\title{
PERFORMANCE MEASUREMENT AND CONTROL IN LOGISTICS SERVICE PROVIDING
}

\author{
Elfriede Krauth, Hans Moonen* \\ Rotterdam School of Management, Department of Decision and Information Sciences \\ Erasmus University Rotterdam, Burg. Oudlaan 50, P.O.Box 1738, 3000 DR, Rotterdam, The Netherlands \\ E-mail: ekrauth@rsm.nl,hmoonen@rsm.nl \\ Authors ranked in alphabetical order. * = Corresponding author (Room F1-26, Telephone: +31 10 408 1403, Fax: +3110408 9010)
}

\author{
Viara Popova, Martijn Schut \\ Department of Computer Science, Faculty of Sciences \\ Vrije Universiteit Amsterdam, De Boelelaan 1081a, 1081 HV, Amsterdam, The Netherlands \\ E-mail:popova@few.vu.nl, schut@cs.vu.nl
}

Keywords: Key Performance Indicators (KPI), Planning Systems, Logistics Service Providers, System Development

Abstract: Output of a planning process is a set of assigned individual tasks to resources at a certain point in time. Initially a manual job, however, in the past decades information systems have largely overtaken this role, especially in industries such as (road-) logistics. This paper focuses on the performance parameters and objectives that play a role in the planning process. In order to gain insight in the factors which play a role in designing new software systems for Logistical Service Providers (LSPs). Therefore we study the area of Key Performance Indicators (KPI). Typically, KPIs are used in a post-ante context: to evaluate a company's past performance. We reason that KPIs should be utilized in the planning phase as well; thus ex-ante.

The paper describes the extended literature survey that we performed, and introduces a novel framework that captures the dynamics of competing KPIs, by positioning them in the practical context of an LSP. This framework could be valuable input in the design of a future generation of information systems, capable of incorporating the business dynamics of today's LSPs.

\section{INTRODUCTION}

Planning is the process of assigning individual tasks to resources at a certain point in time. Originally, planning was a manual task, performed by a human planner. Over the last decades information systems have increasingly taken over this role in industries such as road-logistics; in practice however the human planner has still a considerable role. In order to make the transition from planning input to planning output, a planning system - manual or computerized - must employ the proper objectives to derive to an optimal planning. To gain insight in this area, we consider the Key Performance Indicators (KPI) literature. KPIs are typically used in a post-ante context: to evaluate the past performance of a company. We reason that KPIs could be utilized in the planning phase as well; ex-ante.

The research question we pursue with this paper is: Which are the performance indicators that have an impact on operational performance of logistics service providers? We briefly describe the Logistics Service Providers (LSP) industry and shortly introduce the KPI field (section 2). Then, we undertake a literature review in the areas of supply chain management and LSPs (section 3). Building upon, we compose a framework for logistical KPIs, considering a multi-dimensional and multiple stakeholder perspective (section 4). Section 5 covers validation. Future research directions and conclusions are discussed in section 6.

\section{LOGISTICS SERVICE PROVIDERS AND KPI'S}

The increasing focus on core competencies opened up many business opportunities for Logistics Service Providers (LSPs) (Christopher, 1998). LSPs, often also referred to as Third Party Logistics Service Providers (3PLs), carry out the logistic activities for one or more companies within the supply chain; functioning as an intermediary (Lai et al., 2004). The functions of 3PLs or LSPs can be divided in: warehousing, transportation, customer service, and 
inventory and logistics management (Sink et al., 1996), (Vaidyanathan, 2005).

Logistics service providing is an industry under great pressure. Margins are small, and therefore LSPs continuously seek for opportunities to make their business more profitable. That can be, for example, by scaling up or expanding their activities outside their home country (Lemoine et al. 2003).

Planning and control is crucial for the operations of an LSP: both for the day-to-day operations as well as the more long-term strategic objectives. A good insight in performance information and therewith steering mechanisms for planning is important. Historically, companies concentrated on financial indicators. Nowadays it is widely recognized that non-financial and even non-numerical indicators can give valuable information as well (Brewer et al, 2000, Ittner et al., 2003). Such indicators though are more difficult to measure and compare.

Selecting the right indicators for measuring (and steering!) however is rather complicated. A full set of indicators could result in a huge amount of data which would require a lot of efforts and high costs both in acquiring and analyzing. Another difficulty is that it is not uncommon that the selected indicators turn out to be conflicting - improving one may worsen another.

Performance indicators are to a large extent domain specific. Our research focuses on the area of third-party logistics. But even here no unique subset of indicators can be selected. The choice is company specific and depends on the goals, state and orientation of the company. Therefore it is worthwhile to first concentrate efforts on providing aid in the selection process. The existing literature on performance measurement in logistics provides a large number of potentially useful indicators.

\section{LITERATURE REVIEW}

KPIs are used to evaluate the past performance of a company: making it possible to compare performance with previous periods of measurement, or industry standards or even individual competitors. Consequently, any logistical system should try to optimize and steer its decisions to the metrics it later shall be evaluated upon. A clear insight into the factors that drive logistical operations provides us with adequate planning objectives.

In this paper, we review the different theories and empirical findings known in literature on KPIs in (road-) logistics. We specifically include elements such as the multi-dimensionality of companies (several hierarchical planning levels as well as relevant business functions per company), general business performance versus individual order performance, and the principles of supply chain management (steering a chain of companies versus solely steering one's own company). Note that the perception of performance is relative: cost efficiency may be one of the important measures for an LSP, still this might not be what the shippers and consignees desire - they would instead prefer high quality and low price (Lai et al., 2004).

In the literature we identified two major perspectives. First, there is a clear split between performance indicator related research that focuses on internal operations of an individual firm, versus literature that takes the supply chain perspective and seeks to optimize inter-organizational performance. For one exception we refer the reader to Gibson et al. (2002), which compared how shippers and carriers rank service. The second perspective relates to the use of performance indicators; in general the indicators are used either at the strategic level, for performance evaluation, or at the highly operational level, for planning and control. In the next sections we review the different sources of literature.

\subsection{Supply chain performance}

LSPs are specialists in supply chain management, and are generally well aligned with the type of supply chain they serve. Fisher (1997) makes a split between efficient and responsive supply chains. Christopher et al. (2002) make a similar distinction into lean and agile. Weber (2002) is using a hierarchical model to measure supply chain agility. The Supply-Chain Operations Reference-model (SCOR) offers a model with standards to describe supply chains (SCOR, 2003). Measurements which can be used to measure efficiency or leanness of LSPs include fill rate of delivery plans, empty-toloaded backhaul mile index, equipment utilization rates (hours), equipment utilization rates, vehicle maintenance costs. Metrics to measure responsiveness or agility include export shipment processing time, delivery performance to customer requested date, customs clearance time.

A strong partnership emphasizes direct, longterm collaboration, encouraging mutual planning and problem solving efforts.

Another important point is the use of information systems (Sander, et al. 2002); as well as the type of systems. Information systems support the integration of inter-organizational processes (Hammer, 2001). For an LSP information systems revolve around four major players: the LSP's customer, the customer's clients, the customer's suppliers and alliances, and the LSP provider itself (Vaidyanathan, 2005). Ross (2002) shows that IT investment can have a positive 
impact on market performance as a result of better coordination in the value chain. However, putting such a high level of collaboration into practice is not easy. Both information quality and relationship commitment play an important role (Moberg et al, 2002). As Kemppainen et al. (2003) suggest; it is neither feasible nor profitable to have strong collaboration with all supply chain partners. LSPs should select key customers and focus on these relationships. This then might result in different types of inter-organisational systems: hierarchies and/or markets (Graham et al., 1994), (Toni et al, 1994), (Lewis et al, 2000).

\subsection{Performance management from an internal company perspective}

Whereas supply chain performance evaluation can take many identities as has been shown above, researchers agree on internal measurement, cost calculation and performance evaluation methods. Company-centred performance management focuses on the measurement and evaluation of decision making on company performance.

In the 1990s Van Donselaar et al. (1998) performed a large-scale study in the transportation and distribution sector in the Netherlands. They focused on logistics performance from the provider's point of view - where they make a division between distribution and transportation. Their findings include the attractiveness of long trips for long-distance transportation (which might be influenced in the order-intake process). Furthermore they show that a lower percentage of empty miles (of total miles driven) leads to better results. Finally, combining (international) shipments might be beneficial, though it consumes more handling time.

UPS executive Peter Bromley (2001) lists the big five KPIs important for UPS Logistics: on-time receiving, on-time shipping and delivery, order accuracy, inventory accuracy, returns cycle time. Although low costs are important for UPS, the perfect customer experience (through a perfect service) seems to direct its business processes; for other LSPs this may be different.

Similar findings were reported by Menon et al (1998) who list the most important factors relevant for customers in their selection of an LSP. Most important are: speed and reliability, loss and damage rate and freight rates (tariffs).

Delivery performance can be measured by ontime delivery. This determines whether a perfect delivery has taken place or not, it thus measures customer service. Stewart (1995) identifies the following as the measures of delivery performance: delivery-to-request rate, delivery-to-commit date, order fill lead-time and goods in transit. Quality and the way the information is exchanged determine the delivery performance to a large extent; possible performance indicators are: number of faultless invoices, flexibility of delivery systems to meet particular customer needs. Measures of customer service and satisfaction are flexibility, customer query time, and post transaction measures of customer service. See (Fowkes et al. 2004) for a discussion on the reasons for delay and how reliability and predictability is valued in industry.

Mentzer et al. (1991) study performance evaluation in logistics. They identify a list of performance measures in five sub-areas of logistics. They differentiate between: labour measures (loading, driving, general labour), cost measures, equipment measures, energy and transit-time measures.

Closely related to performance management, are modern accounting methods, such as Activity Based Costing (ABC) (Pirttila et al., 1995; Themido et al., 2001). ABC differs from traditional cost accounting by tracing costs to products according to the activities performed on them. $\mathrm{ABC}$ has gained acceptance within manufacturing; however, most companies have not yet extended $\mathrm{ABC}$ to logistics operations. In theory, the application of $\mathrm{ABC}$ within an LSP would make it possible to trace costs to specific orders, customers, or supply channels.

\subsection{Planning levels}

A company is usually divided into the levels strategic, tactical and operational. Gunasekaran et al. (2001) assigned metrics to the appropriate management level. Van Donselaar et al. (1998) distinguish between segments, which are marked by the different services that are offered to customers. The relevant costs on segment level were variable costs (fuel, tyres, maintenance, etc.), direct costs (depreciation, insurance, leasing, etc.) and driver wages.

Lohman et al. (2004) perceive performance measurement systems as process control systems. If there is discrepancy between the actual and desired value of a metric, knowledge about the behaviour of the organization is used to modify the process. At the tactical or strategic level the control loop is used to evaluate the operational level and adjust its goals.

\subsection{Measuring the un-measurable}

It is compelling to note that most literature focuses on numerical factors such as: cost, time, faults, IT utilization. Environmental factors, customer perceptions, employee happiness, et cetera are 
hardly covered in logistical performance indicator literature. An exception is the balanced scorecard which provides a formalized mechanism to achieve a balance between non-financial and financial results across short-term and long-term horizons and is based on the notion that companies have to aim at a true integration of marketing, production, purchasing, sales and logistics (Brewer et al., 2000). The balanced scorecard distinguishes four main perspectives (Kaplan et al., 1992): customer, internal, financial, innovation and learning. The managers need to create their own version of the balanced scorecard and concentrate on the most critical measures.

Knemeyer, et al. (2003) study the perspective of a customer. If the customer perceives that the LSP focuses on the interaction between the companies and is concerned with winning and keeping the customer, the relationship can be strengthened. Stank et al. (2003) examine how relational, operational and cost performance relate to customer satisfaction, loyalty and market share.

The internal business perspective translates the customer perspective into what the company must do in order to meet its customer's expectations. But the targets for success keep changing; and thus innovation is needed. For LSPs innovations can include additional activities, regions, transport modes and communication systems e.g. RFID or WebServices (Chapman et al., 2003, Lemoine et al., 2003). Financial indicators measure if the company's strategy, implementation and execution contribute to bottom-line improvement.

\section{OUR FRAMEWORK}

The literature overview presented in the previous section supports the view that a new framework for performance indicators can be beneficial in the area of third party logistics. We consider different points of view (both internal and external) on the company's performance. Figure 1 presents the general scheme of our framework. On the horizontal axis we separate the different viewpoints corresponding to the parties involved. The internal point of view is represented by the two parties within the company - management and employees. The external point of view shows the perspective of the customer and the society.

The motivation for including four different points of view comes from the fact that in many cases they will be conflicting and, in order to achieve a balance, the management should be aware of the needs and desires of all parties involved. Consider for example the prices for the logistics services the company offers. Increasing the price will bring more profit which is desirable for the company. The customer, however, prefers low prices. The society on the other hand is clearly not so concerned with prices alone but more with the economic climate as a whole, e.g. how to increase the competition, fight monopolies, etc. Employees are in general not so concerned with the prices but with their work conditions. Another example would be labour efficiency. Management is interested in maximum utilization of labour which, without applying restrictions, will lead to overexploitation. This naturally comes in conflict with the point of view of the employees. The society might be concerned with cases of overexploitation on a large scale that leads to drastic increases in accidents, strikes disrupting traffic or health insurance issues.

The vertical axis in Figure 1 divides the performance indicators in long-term and short-term. This distinction has been previously used in other research (e.g. Gunasekaran et al, 2001) and is accepted as a meaningful division that the decision makers find applicable. Short term indicators can be measured for example within the period of a month. The final choice of short term indicators depends on organizational strategy and measurements costs. For instance, an organization aiming at maximizing its total number of driven kilometers would want to report this on a daily basis. Progress in information and communication technology might lower costs for more granular measurements. Long term performance indicators are measured over longer periods of time.

The classification discussed so far is very general. It incorporates all relevant points of view but does not provide structure within these viewpoints. Thus we extend it in this direction. An extra extension has been added for the management point of view, the KPI scheme has been further split in four categories; see the lower part of Figure 1. The reason for only enriching the management point of view is that we expect it to accumulate a richer collection of indicators where further refinement will be necessary. We differentiate between the following four categories:

Effectiveness - Effectiveness measures the capability of producing an intended result. It thus concerns the 'outside' of the organization - what results does the organization achieve?

Efficiency - Efficiency is the measurement for producing results taking into account used resources. It thus refers to the 'inside' of the organization how does the organization achieve its results? We may also say that efficiency measures the ratio between input and output.

Satisfaction - Satisfaction represents the human factor in our model. All organizational achievements 
may be optimal regarding effectiveness and efficiency, the people in the organization should still be able to do their work to some degree of satisfaction. In this way, it makes the performance optimization problem of the organization more constrained.

IT and innovation - An organization must also be concerned with its future performance. As such, innovation and IT utilization are indispensable factors for measuring long term performance. An organization that is working optimal now may not be the best tomorrow if it does not take its own circumstances into reconsideration constantly.

We applied this framework to our extensive collection of performance indicators; for results see Table 1.

\section{FRAMEWORK EVALUATION}

We present here preliminary validation results although validation is at the time of writing not yet completed. We conducted an expert interview to cross-validate our model with feedback from industry. We plan to conduct field studies with two LSPs (i.e. with management and planners). After finishing our evaluation, we intend to use the framework and its indicators in the development of a new agent-based software system for road-logistics planning.

\subsection{Expert interview}

The interviewee prepared for the interview by reading a draft version of this article, i.e. the literature review, and the definition part of the framework. The semi-structured interview lasted for one-and-a-half hours. The interviewer started with a short introduction. He explained in ten minutes what the purpose was of this interview, what has been done so far, and what future plans were. Furthermore he made clear why especially this interviewee was selected. Over the next seventy-five minutes, the interviewee gave his vision on performance measurement and performance indicators. His thoughts were guided by twenty years of logistical industry experience. At the end of the interview, the interviewer used five minutes to summarize the points discussed in the interview, which were confirmed by the interviewee. The results of the interview are presented below, in Table 2 ; it contains a summary of the most relevant aspects discussed during the interview; before publication it was checked with the interviewee.

Figure 1: High-level framework to cluster KPI's relevant for LSPs

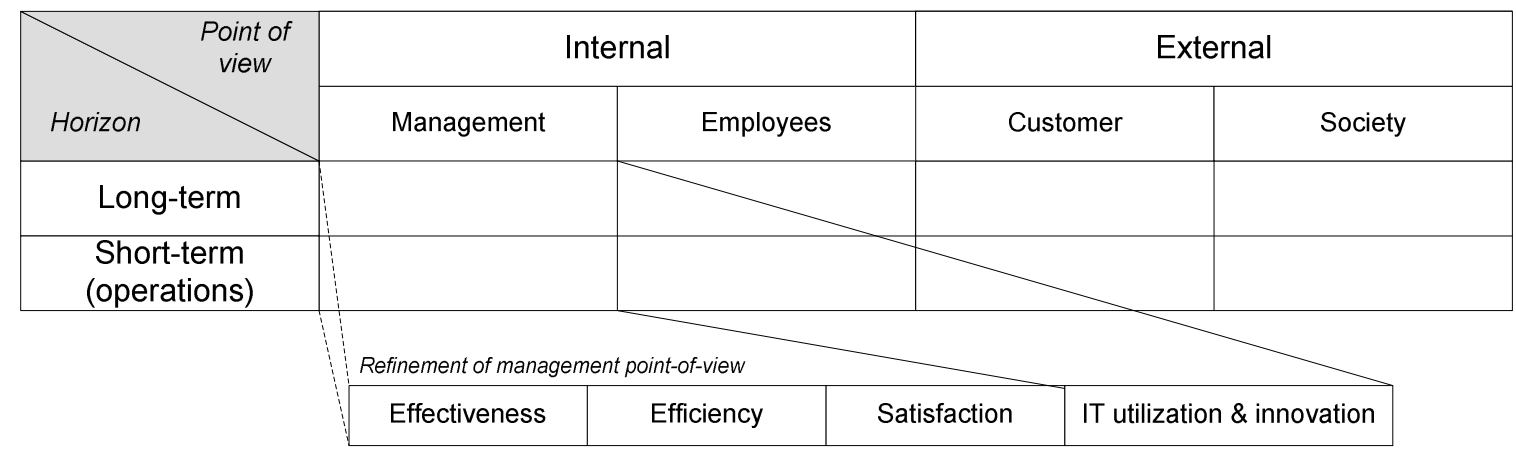

Table 1: List of clustered performance indicators for LSPs

\begin{tabular}{|c|c|c|}
\hline \multicolumn{3}{|c|}{ Internal perspective - Management point of view } \\
\hline \multicolumn{3}{|l|}{ Effectiveness } \\
\hline Revenue $\uparrow$ & Total number of orders $\uparrow$ & Long term plans availability / development $\uparrow$ \\
\hline Profit margins $\uparrow$ & Number of customers $\uparrow$ & Market share width $\uparrow$ \\
\hline Capacity utilization $\uparrow$ & Number of new customers $\uparrow$ & Number of markets that have been penetrated $\uparrow$ \\
\hline Km per day $\uparrow$ & Number of regular customers $\uparrow$ & Successful contacts $-\%$ of successful deals out of the initial offers $\uparrow$ \\
\hline Labour productivity $\uparrow$ & Number of profitable customers $\uparrow$ & Effectiveness of distribution planning schedule $\uparrow$ \\
\hline Price $\uparrow$ & Continuous improvement, rate $\uparrow$ & $\%$ of orders scheduled to customer request $\uparrow$ \\
\hline Turnover per $\mathrm{km} \uparrow$ & Product range $\uparrow$ & $\%$ of supplier contracts negotiated meeting target terms and \\
\hline Number of deliveries $\uparrow$ & Plan fulfilment $\uparrow$ & conditions for quality, delivery, flexibility and cost $\uparrow$ \\
\hline Benefit per delivery $\uparrow$ & Total loading capacity (for trucks) $\uparrow$ & Competitive advantage $\uparrow$ \\
\hline Trips per period $\uparrow$ & On-time delivery performance $\uparrow$ & \\
\hline Perfect order fulfilment $\uparrow$ & & \\
\hline
\end{tabular}




\begin{tabular}{|c|c|c|}
\hline \multicolumn{3}{|l|}{ Efficiency } \\
\hline $\begin{array}{l}\text { Total distribution cost } \downarrow \\
\text { Labour utilization } \uparrow \\
\text { Overhead percentage } \downarrow \\
\text { Overtime hours } \downarrow \\
\% \text { Absent employees } \downarrow \\
\text { Salaries and benefits } \downarrow \\
\text { Controllable expenses } \downarrow \\
\text { Non-controllable expenses } \downarrow \\
\text { Customer service costs } \downarrow \\
\text { Order management costs } \downarrow \\
\text { Inventories } \downarrow \\
\text { Number of trucks in use } \uparrow \\
\text { Total delivery costs } \downarrow \\
\end{array}$ & $\begin{array}{l}\text { Average fuel use per km } \downarrow \\
\text { Average delivery re-planning time } \downarrow \\
\text { Marketing costs } \downarrow \\
\text { Failure costs } \downarrow \\
\text { Prevention costs } \downarrow \\
\text { Appraisal/Inspection costs } \downarrow \\
\% \text { of failed orders } \downarrow \\
\% \text { of realized km out of planned km } \uparrow \\
\text { Performance measurements costs } \downarrow \\
\text { Human resource costs } \downarrow \\
\text { Variable asset costs } \downarrow \\
\text { Fixed asset costs } \downarrow \\
\text { Information system costs } \downarrow\end{array}$ & $\begin{array}{l}\text { Overhead/management/administrative costs } \downarrow \\
\text { Quality of delivery documentation per truck/driver } \uparrow \\
\text { Effectiveness of delivery invoice methods } \uparrow \\
\% \text { orders / lines received with correct shipping documents } \uparrow \\
\% \text { product transferred without transaction errors } \uparrow \\
\text { Item/Product/Grade changeover time } \downarrow \\
\text { Order management costs } \downarrow \\
\text { Supply chain finance costs } \downarrow \\
\text { Total supply chain costs } \downarrow \\
\text { Total time in repair (for trucks) } \downarrow \\
\text { Ratio of realized orders vs. requested orders } \uparrow \\
\text { Average delivery planning time } \downarrow\end{array}$ \\
\hline \multicolumn{3}{|l|}{ Satisfaction } \\
\hline $\begin{array}{l}\text { Attrition of drivers } \downarrow \\
\text { Morale, motivation of personnel } \\
\uparrow\end{array}$ & $\begin{array}{l}\text { On-time delivery performance } \uparrow \\
\text { Number of customer complains } \downarrow \\
\text { Overall customer satisfaction } \uparrow\end{array}$ & $\begin{array}{l}\% \text { of orders scheduled to customer request } \uparrow \\
\text { Overall employees satisfaction } \uparrow \\
\text { Overall society satisfaction } \uparrow\end{array}$ \\
\hline \multicolumn{3}{|l|}{ IT and innovation } \\
\hline $\begin{array}{l}\text { Information system costs } \downarrow \\
\text { Up-to-date performance } \\
\text { information availability } \uparrow \\
\text { Utilization of IT equipment } \uparrow \\
\text { IT training costs } \downarrow\end{array}$ & $\begin{array}{l}\text { Number of new products in the range } \uparrow \\
\% \text { of information exchange through IT } \uparrow \\
\% \text { of employees with IT training } \uparrow \\
\text { Availability of IT equipment } \uparrow\end{array}$ & $\begin{array}{l}\% \text { of information management assets used / production assets } \uparrow \\
\% \text { of invoice receipts and payments generated via EDI } \uparrow \\
\text { Average time for new products development } \downarrow \\
\text { Average costs for new product development } \downarrow\end{array}$ \\
\hline \multicolumn{3}{|c|}{ Internal perspective - Employee's point of view } \\
\hline $\begin{array}{l}\text { Km per trip } \downarrow \\
\text { Working conditions } \uparrow\end{array}$ & Weight to (un)load per labour hour $\downarrow$ & Salaries and benefits $\uparrow$ \\
\hline \multicolumn{3}{|c|}{ External perspective - Customer's point of view } \\
\hline $\begin{array}{l}\text { Transportation price } \downarrow \\
\text { Insurance price } \downarrow \\
\text { Primary services price } \downarrow \\
\text { Goods safety } \uparrow \\
\text { Product variety } \uparrow \\
\text { Response time } \downarrow\end{array}$ & $\begin{array}{l}\text { Transparency for a customer } \uparrow \\
\text { Possible types of communication } \uparrow \\
\text { Available types of goods insurance } \uparrow \text { Order } \\
\text { size flexibility } \uparrow \\
\text { Timeliness of goods delivery } \downarrow\end{array}$ & $\begin{array}{l}\text { Services variety } \uparrow \\
\text { Order configuration flexibility } \uparrow \\
\text { Possibility to change order details } \uparrow \\
\text { Additional services price (priority transportation) } \downarrow \\
\text { Contact points (number of people to contact) } \downarrow\end{array}$ \\
\hline \multicolumn{3}{|c|}{ External perspective - Society's point of view: } \\
\hline $\begin{array}{l}\text { Level of CO2 emission } \downarrow \\
\text { Society satisfaction } \uparrow \text { Wasting } \\
\text { resources } \downarrow \\
\text { Recycling level } \downarrow \\
\text { Employees satisfaction } \uparrow \\
\text { Disaster risk } \downarrow\end{array}$ & $\begin{array}{l}\text { Solid particles emission } \downarrow \\
\text { Taxes to the national treasury } \uparrow \\
\text { Participation in charitable actions } \uparrow \\
\text { Reputation of a company } \uparrow \\
\text { Road maintenance costs } \downarrow \\
\text { Number of available work places } \uparrow\end{array}$ & $\begin{array}{l}\text { Competition level among similar companies } \uparrow \\
\text { Care for animals/children around } \uparrow \\
\text { Use of innovation technologies } \uparrow \\
\text { Development of innovation technologies } \uparrow \\
\text { Cooperation with other companies } \uparrow\end{array}$ \\
\hline
\end{tabular}

\section{Table 2: Expert Interview}

In traditional Operations Research (OR), operations are often rated and optimized upon a small set of parameters only sometimes only one single parameter. This results however in non-optimal system behaviour. Consider the example of empty-kilometer minimization. This optimization often results in trucks standing still, waiting for a next order (preferably with a starting point equal to the place of waiting). Trucks do not anticipate on the next order (in a more fruitful region). Often waiting time does cost money as well - the driver needs to be paid and the truck could have been utilized for other purposes. Reviewing single optimization parameters can hardly be seen separate from other indicators, as the following indicates: Let us consider an LSP that has a truck driving around with only one small package - so, it uses only $5 \%$ of its carriage capacity - utilizing a very inefficient route, with lots of detours. It is however not driving around empty - so from an empty-miles perspective this truck operates very effective. Although we do realize that the truck could have carried more cargo, and the route it took could have been more efficient. However, we do not know yet whether the customer is actually paying for this trip - because if so, no LSP would mind to have a truck driving around via an inefficient route, with only little cargo as long as the customer is paying a good price.

Not all indicators do have a direct translation in costs, or financial measurements, but do translate in, for example, extra appreciation from the customer. An interesting example is Cehave - a Netherlands based organization active in the agribusiness. When delivering feed products to farmers, farmers prefer and value it to be the first farm on the deliveryroundtrip, since with each extra visit (between Cehave's plant, and the farm) the risk on animal diseases and infections rises. The paradox however is that, although farmers prefer the service of being the first customer, they are not willing to pay for this service.

Agility is more-and-more required for LSPs business operations. It is very important to have a flexible business infrastructure, capable of quickly reacting and adapting to changes in operations: new orders, re-routing of a truck, or handling changes in the environment (such as a traffic jam). Therefore quick react capabilities are of true importance; measuring these however is a complex matter.

Planning systems targeted at such industries could well be build by using agent technology, and dynamic systems (control) structures; utilizing measurement and reaction mechanisms to derive to smart decisions. [We] believe that smart 
local decision making, making the right decisions at the right moment and right place are likely to result in well behaving planning systems. Feedback plays an important role in such systems. Performance measurement should not only look at the parameter as such, but also at the way those parameters change (and behave) over time - thus be aware of the first or second derivative of the function as well.

The framework as presented in this paper is very interesting. It is finally an attempt to have a complete scheme, looking beyond just financial indicators, and especially dedicated for the logistical industry. It measures more than solely costs, like it also captures perceptions (of management, customers, employees at different levels, et cetera). A very useful division is the split between the strategic, tactical, and operational time-domains. It might furthermore help in overcoming problems in supply chains that want to assess chain wide performance. However, some adjustments and generalizations might be needed.

Critical notes on the work include: a subdivision/refinement as was made for the classification of the management point-of-view (see Table 2) should be made for all the categories as mentioned in the framework, thus including employees, customer and society as well. Therewith the framework becomes three-dimensional. Be aware that optimal, does not mean the same to all companies. Optimal for one company, can be far from optimal for another company.

Interesting aspect of the presented work is that it could serve as a tool that makes performance indicators, and therewith system-control a discussable issue in an organization - which would be a real valuable tool to evaluate current systems, and to design future systems. The true advantage of this approach is that it could be relatively easy translated into an agentbased software system. With software agents monitoring and controlling single performance indicators, and steering upon these.

\section{CONCLUSIONS}

The contribution of this paper is twofold. Firstly, we present a literature survey on the concept of performance indicators in logistics. Secondly, we present a framework capturing the dynamics of performance indicators for LSPs including an extensive list of LSP performance indicators.

The literature survey identifies a number of studies on performance measurement/evaluation for logistics. However, these studies are mainly on a particular area or case and are focused on external and quantitative indicators. Our review has considered the areas of supply chains, internal company performance, planning and qualitative indicators.

The framework that we present is a first step towards our long term aim to use performance indicators ex-ante rather than post-ante. The model considers indicators along two main dimensions. On the one hand we look at the perspective: internal (management, employees) and external (customer, society); on the other hand we classify indicators as short-term or long-term. We identify the cost of measurement of an indicator as essential in choosing whether an indicator is eligible for pre-ante monitoring and analysis. We have validated our framework with a domain expert, and have planned multiple case-studies and interviews for validation as future work.

Other directions for future work include obtaining more insight in the relationships between the indicators as well as the relationships between indicators on different aggregation levels. The knowledge gained will be applied in the DEAL project - which aims at the development of an agent-based software system for road-distribution planning. In such a system we represent the involved logistical parties as agents operating within a multi-agent system. In order to give the agents the proper decision objectives, insight in logistical KPIs is needed. Finally, we are currently developing a formal language for expressing the relationships between the indicators and reasoning about these, drawing inspiration from the field of requirements engineering.

\section{ACKNOWLEDGEMENTS}

This work is part of DEAL (Distributed Engine for Advanced Logistics) supported as project EETK01141 under the Dutch EET programme. For this particular paper we are very grateful for the contributions of Jos van Hillegersberg, Peet van Tooren, Jan Treur, Steef van de Velde, and Pinar Yolum.

\section{REFERENCES}

Brewer, P. C. \& Speh, T. W. (2000). Using the balanced scorecard to measure supply chain performance. Journal of Business Logistics 21(1):75-93.

Bromley, P. (2001). A Measure of Logistics Success. Logistics Quarterly 7(3).

Chapman, R. L., C. Soosay, Kandampully, M. (2003). "Innovation in logistics services and the new business model." International Journal of Physical Distribution and Logistics Management 33(7): 630-650.

Christopher, M (1998) Logistics and Supply Chain Management: strategies for reducing cost and improving 
service 2nd Edition. Financial Times / Prentice-Hall, London.

Christopher, M., \& Towill, D. R. (2002). Developing Market Specific Supply Chain Strategies. International Journal of Logistics Management, 13(1): 1-14.

Donselaar, K. v., Kokke, K. and Allessie, M. (1998). Performance measurement in the transportation and distribution sector. International Journal of Physical Distribution \& Logistics Management 28(6): 434-450.

Fisher, M. L. (1997). What is the Right Supply Chain for your Product? Harvard Business Review (March/April): 105116.

Fowkes, A. S., P. E. Firmin, et al. (2004). How Highly Does the Freight Transport Industry Value Journey Time Reliability - and for What Reasons? International Journal of Logistics - Research and Applications 7(1): 33-43.

Gibson, B. J., S. M. Rutner, et al. (2002). Shipper-carrier partnership issues, rankings and satisfaction. International Journal of Physical Distribution and Logistics Management 32(8): 669-681.

Graham, T. S., dougherty, P. J., \& Dudley, W. N. (1994) The long term strategic impact of purchasing partnerships. International Journal of Purchasing and Materials Management, 32(4): 797-805.

Gunasekaran, A., Patel, C. and Tirtiroglu, E. (2001). Performance measures and metrics in a supply chain environment. International Journal of Operations \& Production Management 21(1/2): 71-87.

Hammer, M. (2001). The superefficient company. Harvard Business Review 79(8): 82.

Ittner, C. D., \& Larcker, D. F. (2003) Coming Up Short on Nonfinancial Performance Measurement. Harvard Business Review, 81(11): 88-96.

Kaplan, R. S., \& Norton, D. P. (1992). The Balanced Scorecard - Measures that Drive Performance. Harvard Business Review 75(2): 70-79.

Kemppainen, K. and A. P. J. Vepsaelaeinen (2003). Trends in industrial supply chains and networks. International Journal of Physical Distribution and Logistics Management 33(8): 701-719.

Knemeyer, A. M., Corsi, T. M., \& Murphy, P. R. (2003). Logistics outsourcing relationships: Customer perspectives. Journal of Business Logistics, 24(1):77-110.

Lai, K.H., Ngai, E.W.T., Cheng, T.C.E. (2004), An empirical study of supply chain performance in transport logistics, International Journal of Production Economics 87: 321331.

Lemoine, W. and L. Dagnaes (2003). Globalisation strategies and business organisation of a network of logistics service providers. International Journal of Physical Distribution and Logistics Management 33(3): 209-228.
Lewis, I., Talalayevsky, A. (2000). Third-Party Logistics: Leveraging Information Technology. Journal of Business Logistics; 21, 2: 173-185

Lohman, C., Fortuin, L., Wouters, M. (2004). Designing a performance measurement system: A case study. European Journal of Operational Research 156:267-286.

Menon, M.K., McGinnis, M.A., Ackerman, K.B. (1998) Selection Criteria for Providers of Third-Party Logistics Services: an Exploratory Study, Journal of Business Logistics 19(1): 121-137

Mentzer, J. T. and Konrad, B. P. (1991). An efficiency / effectiveness approach to logistics performance analysis. Journal of Business Logistics 12(1): 33-62.

Moberg, C. R., B. D. Cutler, et al. (2002). Identifying antecedents of information exchange within supply chains. International Journal of Physical Distribution and Logistics Management 32(9): 2002.

Pirttila, T., Hautaniemi, P. (1995). Activity-based costing and distribution logistics management, International Journal of Production Economics 41: 327-333.

Ross, A. (2002). A multi-dimensional empirical exploration of technology investment, coordination and firm performance. International Journal of Physical Distribution and Logistics Management 32(7): 591-609.

Sanders, N. R. and R. Premus (2002). IT Applications in Supply Chain Organizations: a Link between Competitive Priorities and Organizational Benefits. Journal of Business Logistics 23(1): 65-83.

Sink, H. L., Langley Jr., C. J., \& Gibson, B. J.(1996). Buyer observations of the US third-party logistics market. International Journal of Physical Distribution \& Logistics Management, 26(3): 38-46.

SCOR (2003); Supply-Chain Operations Reference Model SCOR Version 6.0; April 2003.

Stank, T. P., Goldsby, T. J., et al. (2003). Logistics service performance: estimating its influence on market share. Journal of Business Logistics 24(1): 27-55.

Stewart, E. (1995) Supply chain performance benchmarking study reveals keys to supply chain excellence, Logistics Information Management, 8(2): 38-44.

Themido, I., Arantes, A., Fernandes, C., Guedes, A.P. (2000). Logistics costs case study - an ABC approach, Journal of the Operational Research Society 51:1148-1157.

Toni, A. D., Nissimbeni, G., \& Tonchia, S. (1994). New trends in supply environment. Logistics Information Management, 7(4): 41-50.

Vaidyanathan, G. (2005). A Framework for Evaluating ThirdParty Logistics, Communications of the ACM, January 2005 48, 1: 89-94

Weber, M. M. (2002). Measuring supply chain agility in the virtual organization. International Journal of Physical Distribution and Logistics Management 32(7): 557-590. 